\title{
Effects of peroxidation products in thermoxidised dietary oil in female rats during rearing, pregnancy and lactation on their reproductive performance and the antioxidative status of their offspring
}

\author{
Corinna Brandsch and Klaus Eder* \\ Institute of Nutritional Sciences, Martin-Luther-University Halle-Wittenberg, Emil-Abderhalden-Straße 26, D-06108 Halle/ \\ Saale, Germany
}

(Received 21 December 2003 - Revised 8 March 2004 - Accepted 14 April 2004)

\begin{abstract}
The present study was performed to investigate whether lipid peroxidation products in thermoxidised dietary oil fed during rearing, pregnancy and lactation influences the reproductive performance of female rats and the antioxidant status of their offspring. Twenty-four female rats were divided into two groups at 4 weeks of age. They were fed diets containing fresh or oxidised oil (the latter prepared by heating at a temperature of $50^{\circ} \mathrm{C}$ for $16 \mathrm{~d}$ ) for 14 weeks. At the age of 12 weeks female rats were mated. The number of total pups and pups born alive was not different between both groups. However, individual pups and litters of dams fed oxidised oil were lighter at birth and gained less weight during the suckling period than those of dams fed fresh oil $(P<0 \cdot 05)$. Pups of dams fed oxidised oil contained less protein and more fat in their carcasses than those of dams fed fresh oil $(P<0.05)$. The milk of dams fed oxidised oil had a lower concentration of triacylglycerols and a lower energy content than that of dams fed the fresh oil $(P<0 \cdot 05)$. The pups of dams fed oxidised oil had higher concentrations of lipid peroxidation products in the liver at birth and day 19 of lactation than those of dams fed fresh oil $(P<0.05)$. In conclusion, the present study shows that feeding oxidised oil with a high concentration of lipid peroxidation products to female rats during rearing, pregnancy and lactation influences the development and antioxidant status of fetus and suckling pups.
\end{abstract}

Thermoxidised fat: Lactation: Lipid peroxidation: Rat

PUFA are labile compounds. Under the promoting effects of high temperature, $\mathrm{O}_{2}$, light or metal catalysts they undergo lipid peroxidation. Human Western-type diets are usually rich in lipid peroxidation products, because of the high preference for fried foods and the widespread fast-food industry. Many studies on the physiological effects of oxidised lipids have been carried out in several animal species (Blanc et al. 1992; Borsting et al. 1994; Engberg et al. 1996). Oxidised oils containing high concentrations of lipid peroxidation products as components of animal diets have been shown to impair growth, cause oxidative stress and affect lipid metabolism (Blanc et al. 1992; Borsting et al. 1994; Engberg et al. 1996). It has been shown that a close relationship between the antioxidant status of pregnant rats or women and their fetuses exists (Viana et al. 1999; Arikan et al. 2001). Strong oxidative stress in pregnant females, such as diabetes mellitus or after chronic ethanol intake, can even lead to deformation and growth retardation of their fetuses (Henderson et al. 1999; Viana et al. 2000; Cederberg et al. 2001). The antioxidant status of lactating female rats is also reflected in the concentrations of various antioxidants, particularly vitamin E, in the milk (Focant et al. 1998; Baldi et al.
2000). Since dietary oxidised oils increase the concentrations of lipid peroxidation products and reduce the antioxidant status of animal tissues (Liu \& Huang, 1995; Eder \& Kirchgessner, 1998), we hypothesise that feeding oxidised oils to pregnant and lactating females adversely affects the antioxidant status and the development of their offspring. Until now, the effects of lipid peroxidation products contained in thermoxidised dietary oils in pregnant and lactating females on the antioxidant status and the development of their offspring have not yet been investigated. The concentrations of the various lipid peroxidation products in heated fats depend on their thermal treatment. In a previous study, we found that an oxidised fat heated at a relatively low temperature over a long time and containing high concentrations of lipid peroxidation products affected the antioxidative status of rats markedly (Eder et al. 2003). We therefore intended to study the effects of an oxidised oil treated in such manner when fed to pregnant and lactating rats as model animals on the body-weight gain and the antioxidant status of their newborn and suckling pups. The assessment of the antioxidant status is particularly difficult in newborn rats, since the amount of sample available for analysis is 
very small. To assess the antioxidant status, we decided to determine the concentrations of several lipid peroxidation products and $\alpha$-tocopherol in the liver. It has been shown that the liver reacts very sensitively to dietary oxidative stress: increased concentrations of lipid peroxidation products and reduced concentrations of $\alpha$-tocopherol in the liver are reliable indicators of oxidative stress (Cho \& Choi, 1994; Ringseis \& Eder, 2002). As well as the concentration of thiobarbituric acid-reactive substances (TBARS), which is a commonly used but very unspecific variable, we proposed to determine the concentrations of lipid hydroperoxides (LHP) and some oxysterols, which are regarded as sensitive variables of oxidative stress (Hermes-Lima et al. 1995; Adachi et al. 2001). In previous studies, it has been observed that feeding oxidised oils influences the lipid metabolism of rats, leading to reduced concentrations of triacylglycerols and cholesterol in the liver (Eder \& Kirchgessner, 1998; Chao et al. 2001; Eder et al. 2003). We were interested to know whether such changes in lipid metabolism occur in the offspring of dams fed an oxidised oil. Therefore, we also proposed to determine the concentrations of cholesterol and triacylglycerols in the livers of newborn and suckling pups.

\section{Material and methods}

\section{Animals}

Twenty-four female Sprague-Dawley rats (Charles River, Sulzfeld, Germany) aged 4 weeks with an average body weight of 81 (SD 3) $\mathrm{g}$ housed individually in Macrolon cages under controlled temperature $\left(23 \pm 2^{\circ} \mathrm{C}\right)$ and a $12 \mathrm{~h}$ light-dark cycle (lights on from 06.00 hours) were used for the experiment. The rats were randomly assigned to one of the two experimental groups of twelve rats each. At an age of 12 weeks, they were paired with adult male Sprague-Dawley rats (Charles River) for $6 \mathrm{~d}$. At the day of parturition, designated as day 1 of lactation, litters were weighed and then adjusted to seven pups per dam. No gender differentiation was done. All experimental procedures described followed established guidelines for the care and handling of laboratory animals.

\section{Diets and feeding}

Throughout the entire experiment one basal diet was used (Table 1). Minerals and vitamins were supplied in sufficient amounts. The type of fat (fresh $v$. oxidised oil) was varied (see p. 269). To adjust the vitamin E content of the diets, the native concentrations of tocopherols in the oils were analysed (Balz et al. 1993). Based on the native concentrations of the oils, diets were supplemented individually with all-rac- $\alpha$-tocopheryl acetate to achieve $50 \mathrm{mg} \alpha$-tocopherol equivalents/kg diet (the biopotency of all-rac- $\alpha$-tocopheryl acetate is considered to be $67 \%$ that of $\alpha$-tocopherol). The oils had a similar fatty acid composition (Table 2). The concentrations of trans-fatty acids, including conjugated linoleic acid isomers, were low and did not differ between both types of oil. The oxidised oil, however, had much higher concentrations of lipid peroxidation products than the fresh oil.
Table 1. Composition of the experimental diet $(\mathrm{g} / \mathrm{kg})$

\begin{tabular}{lr}
\hline Components & $\mathrm{g} / \mathrm{kg}$ \\
\hline Casein & 200 \\
Maize starch & 390 \\
Sucrose & 198 \\
Fat* & 100 \\
Fibre (cellulose) & 50 \\
Mineral mixture† & 40 \\
Vitamin mixture & 20 \\
DL-Methionine & 2
\end{tabular}

* For details of preparation of the test oil, see p. 269.

† Mineral mixture (/ $\mathrm{kg}$ diet): potassium sulfate $8.0 \mathrm{~g}$, calcium carbonate $4.5 \mathrm{~g}$, dicalcium phosphate $18.5 \mathrm{~g}$, sodium chloride $2.6 \mathrm{~g}$, magnesium oxide $1.2 \mathrm{~g}$, ferrous sulfate hydrate $250 \mathrm{mg}$, zinc oxide $38 \mathrm{mg}$, manganese oxide $16 \mathrm{mg}$, copper sulfate pentahydrate $32 \mathrm{mg}$, calcium iodate $0.32 \mathrm{mg}$, sodium selenite pentahydrate $0.66 \mathrm{mg}$, chromium(III) chloride hexahydrate $5.13 \mathrm{mg}$, nickel sulfate hexahydrate $2.24 \mathrm{mg}$, ammonium molybdate tetrahydrate $0.28 \mathrm{mg}$.

$\mp$ Vitamin mixture (/kg diet): all-trans-retinol $1.34 \mathrm{mg}$, cholecalciferol $25 \mu \mathrm{g}$, menadione sodium bisulfite $0.75 \mathrm{mg}$, thiamin hydrochloride $5 \mathrm{mg}$, riboflavin $6 \mathrm{mg}$, pyridoxine hydrochloride $6 \mathrm{mg}$, calcium pantothenate $15 \mathrm{mg}$, nicotinic acid $30 \mathrm{mg}$, folic acid $2 \mathrm{mg}$, biotin $0.2 \mathrm{mg}$, cyanocobalamin $0.025 \mathrm{mg}$, choline chloride $1 \mathrm{~g}$.

Table 2. Characteristics of the dietary oils*

\begin{tabular}{|c|c|c|}
\hline & Fresh oil & Oxidised oil \\
\hline \multicolumn{3}{|l|}{ Composition } \\
\hline Sunflower oil (g/kg fat) & 730 & 800 \\
\hline Linseed oil (g/kg fat) & 150 & 200 \\
\hline Palm oil (g/kg fat) & 120 & - \\
\hline Treatment (temperature, time) & None & $50^{\circ} \mathrm{C}, 16 \mathrm{~d}$ \\
\hline \multicolumn{3}{|c|}{ Major fatty acids ( $\mathrm{g} / 100 \mathrm{~g}$ total fatty acids) } \\
\hline $16: 0$ & $10 \cdot 6$ & 6.9 \\
\hline $18: 0$ & $4 \cdot 0$ & 4.5 \\
\hline $18: 1$ & $24 \cdot 2$ & $25 \cdot 4$ \\
\hline $18: 2 n-6$ & $48 \cdot 9$ & $49 \cdot 4$ \\
\hline $18: 3 n-3$ & 7.9 & $8 \cdot 2$ \\
\hline \multicolumn{3}{|c|}{ Trans fatty acids ( $\mathrm{g} / 100 \mathrm{~g}$ total fatty acids) } \\
\hline trans-9-18: 1 & 0.80 & 0.80 \\
\hline cis-9,trans-11-18:2 & 0.10 & 0.07 \\
\hline trans-10, cis-12-18:2 & 0.07 & 0.05 \\
\hline trans-9, trans-11-18:2 & 0.32 & 0.28 \\
\hline \multicolumn{3}{|l|}{ Peroxidation products } \\
\hline \multicolumn{3}{|l|}{ Before inclusion in the diet } \\
\hline Peroxide value $\left(\mathrm{mEq} \mathrm{O}_{2} / \mathrm{kg}\right)$ & 5 & 754 \\
\hline Lipid hydroperoxides (mmol/kg) & 4 & 424 \\
\hline Conjugated dienes $(\mathrm{mmol} / \mathrm{kg})$ & 9 & 275 \\
\hline TBARS $(\mathrm{mmol} / \mathrm{kg})$ & $<0.1$ & 30.6 \\
\hline Total carbonyls (mmol/kg) & 7 & 110 \\
\hline Total polar compounds (\%) & 2.5 & 38.7 \\
\hline Acid value $(\mathrm{g} \mathrm{KOH} / \mathrm{kg})$ & $1 \cdot 0$ & $2 \cdot 0$ \\
\hline \multicolumn{3}{|l|}{ After inclusion in the diet } \\
\hline Peroxide value $\left(\mathrm{mEq} \mathrm{O}_{2} / \mathrm{kg}\right)$ & 20 & 727 \\
\hline Lipid hydroperoxides (mmol/kg) & 5 & 504 \\
\hline Conjugated dienes $(\mathrm{mmol} / \mathrm{kg})$ & 12 & 242 \\
\hline TBARS $(\mathrm{mmol} / \mathrm{kg})$ & $1 \cdot 0$ & $36 \cdot 9$ \\
\hline Total carbonyls (mmol/kg) & 9 & 106 \\
\hline Total polar compounds (\%) & $7 \cdot 0$ & $36 \cdot 8$ \\
\hline
\end{tabular}

TBARS, thiobarbituric acid-reactive substances.

* For details of oils, see p. 269.

Diets were prepared by mixing the dry components with oil and water and subsequent freeze-drying. The residual water content of the diet was $<50 \mathrm{~g} / \mathrm{kg}$ diet. Diets were prepared freshly every week and stored at $4^{\circ} \mathrm{C}$. The rats were fed once daily at 08.00 hours. Water was freely available from nipple drinkers. 
In order to standardise the diet intake, a restricted feeding scheme was applied during growth, pregnancy and lactation, whereby each rat received the same amount of diet. The diet intake was slightly below the voluntary diet intake. During growth, from weeks 4 to 12 of age, the daily amount of diet was increased continuously from 8 to $14 \mathrm{~g}$. In their thirteenth week of life, when they were paired with adult male rats, the female rats had free access to the diet. Throughout the pregnancy, each rat received $13 \mathrm{~g} \mathrm{diet} / \mathrm{d}$. During lactation (from day 1 to 19 ), the daily amount of diet was increased continuously from 10 to $35 \mathrm{~g}$.

\section{Preparation of the test oils}

The basal oil to prepare the oxidised oil was sunflower oil-linseed oil (80:20, w/w), which was chosen to supply the rats with sufficient amounts of linoleic acid and $\alpha$-linolenic acid. This oil mixture was poured into a quartz-glass beaker and heated at $50^{\circ} \mathrm{C}$ in a drying oven for $16 \mathrm{~d}$. Throughout the heating process, air was continuously bubbled through the oil. This treatment caused a reduction of the concentration of PUFA in the oil from 64.6 to $57.6 \mathrm{~g}$ / $100 \mathrm{~g}$ fatty acids and a complete loss of tocopherols, and raised the concentrations of lipid peroxidation products in the oil. We planned to equalise the fatty acid composition of the fresh and the oxidised oil. Therefore, the fresh oil was composed of sunflower oil-linseed oil-palm oil (73:15:12, by wt).

\section{Analysis of the test oils}

The fatty acid composition of the oils was determined by GC using a Hewlett Packard system (HP 5890; Hewlett Packard GmbH, Waldbronn, Germany) as described by Brandsch et al. (2002). The extent of lipid peroxidation of the oxidised oil was determined by assaying the peroxide value (Deutsche Gesellschaft für Fettwissenschaft, 1994), the concentration of TBARS (Sidwell et al. 1954), the concentration of conjugated dienes (Recknagel \& Glende, 1984), the concentration of LHP (HermesLima et al. 1995), the acid value (Deutsche Gesellschaft für Fettwissenschaft, 1994), the percentage of total polar compounds (International Union of Pure \& Applied Chemistry, 2000) and the concentration of total carbonyls (Endo et al. 2001). To determine the concentrations of lipid peroxidation products of the dietary oils after inclusion into the diets, the oils were extracted from the diets with hexane-isopropanol $(3: 2, \mathrm{v} / \mathrm{v})$ according to Hara \& Radin (1978).

\section{Data recording}

The following variables were recorded: body-weight gain and diet intake of female rats throughout the experiment; number of pregnant female rats; number of rat pups born alive and stillborn at the parturition; weights of rat pups and litters at birth and weight of litters at days 7, 14 and 19 of lactation.

\section{Sample collection and analyses}

From each dam, three newborn pups were randomly chosen. The livers of these three pups were excised and pooled; pooled livers were used for analysis of the concentrations of triacylglycerols, cholesterol, TBARS, LHP and $\alpha$-tocopherol. On day 14 of lactation, a milk sample was collected from each dam. After separation from the pups for $1 \mathrm{~h}$, each dam was anaesthetised with ketamin $(75 \mathrm{mg} /$ $\mathrm{kg}$ body weight, intramuscularly) and injected intramuscularly with $1 \mathrm{IU}$ oxytocin to stimulate the milk flow. From each rat, $2-3 \mathrm{ml}$ milk was obtained from all teats within $10 \mathrm{~min}$ through sub-atmospheric pressure. In the milk samples, concentrations of triacylglycerols, protein, lactose, LHP, $\alpha$-tocopherol and the antioxidant capacity were determined. On day 19 of lactation the dams were killed by decapitation under light anaesthesia with diethyl ether and livers were excised. In the livers, the concentrations of triacylglycerols, cholesterol, TBARS, LHP, cholesterol oxidation products and $\alpha$-tocopherol were determined. On day 19 of lactation, two randomly chosen pups from each dam were starved for $3 \mathrm{~h}$ and killed by decapitation under light anaesthesia with diethyl ether. Livers of those two pups were removed and pooled; pooled livers were used for analysis of the concentrations of triacylglycerols, cholesterol, TBARS, LHP, oxysterols and $\alpha$-tocopherol. Carcasses of the two pups were also pooled and used for the analysis of protein and total lipids. Pending analysis, all the samples were stored at $-20^{\circ} \mathrm{C}$.

Lipids. Total lipids in livers were extracted with $n$ hexane-isopropanol $(3: 2, \mathrm{v} / \mathrm{v})$, according to Hara \& Radin (1978). Concentrations of triacylglycerols and cholesterol in lipid extracts were determined using enzymic reagent kits (catalogue no. 1.14856, 1.14830; VWR International, Darmstadt, Germany) according to De Hoff et al. (1978).

Concentration of tocopherols. Tocopherols in livers and milk were analysed by HPLC according to the method of Balz et al. (1993).

Concentrations of thiobarbituric acid-reactive substances. Liver homogenates were mixed with thiobarbituric acid reagent (thiobarbituric acid $(8 \mathrm{~g} / \mathrm{l})$-perchloric acid $(70 \mathrm{~g} / \mathrm{l}), 2: 1(\mathrm{v} / \mathrm{v}))$ and heated for $60 \mathrm{~min}$ at $95^{\circ} \mathrm{C}$. TBARS were extracted with $n$-butanol and absorption was measured at $532 \mathrm{~nm}$ (Halliwell \& Gutteridge, 1989). Concentrations were calculated via a standard curve with 1,1,3,3-tetraethoxypropan and related to the concentrations of cholesterol plus triacylglycerols.

Concentrations of lipidhydroperoxides. Methanolic extracts of livers and milk samples were added to an acidic reaction mixture containing $0.25 \mathrm{~mm}-\mathrm{Fe}$ (II) and $0.1 \mathrm{~mm}$-xylenol orange. After a $30 \mathrm{~min}$ incubation at room temperature the formation of $\mathrm{Fe}(\mathrm{III})-x y l e n o l$ orange (FOX) complex was measured at $560 \mathrm{~nm}$ (Hermes-Lima et al. 1995). Concentrations of LHP were calculated by applying a cumene hydroperoxide standard curve and related to the concentrations of cholesterol plus triacylglycerols.

Cholesterol oxidation products. Concentrations of 7 $\beta$-hydroxycholesterol, 7-ketocholesterol, 25-hydroxycholesterol and $5 \alpha, 6 \alpha$-epoxides were determined in liver lipid extracts by GC-MS in selected ion monitoring mode, according to Mori et al. (1996) as described by Brandsch et al. (2002). Results are expressed in relation to the concentration of total cholesterol. 
Carcass composition. The protein concentration in the carcass was determined by the Kjeldahl method (AOAC International, 2001). The fat concentration in the carcass was determined by the diethyl ether extraction method (AOAC International, 2001).

Concentrations of nutrients, energy content and antioxidative status of the milk. Concentrations of triacylglycerols and lactose in milk were measured using commercial kits (VWR International). Concentrations of protein were determined by the method of Bradford (1976). The energy content of the milk was calculated from the concentrations of protein, fat and lactose according to the general Atwater factors (Atwater \& Bryant, 1900); the following conversion factors were used: lactose $17 \mathrm{~kJ} / \mathrm{g}$, fat $38 \mathrm{~kJ} / \mathrm{g}$, protein $17 \mathrm{~kJ} / \mathrm{g}$. Total antioxidative capacity was measured in diluted samples by using a commercial kit (Immundiagnostik, Bensheim, Germany).

\section{Statistical analysis}

The effect of the treatment on body masses of the newborn pups was analysed with a mixed linear model (procedure mixed, version 8.2; SAS Institute Inc., Cary, NC, USA). The treatment (fresh $v$. oxidised oil) was included as a fixed effect; dams were considered as random effects and the number of pups per litter was used for normalisation. All other effects were analysed by Student's $t$ test. Mean values were considered significantly different for $P<0 \cdot 05$.

\section{Results}

\section{Diet intake and body-weight gain of female rats}

The diet intake was identical for each rat in this experiment due to the standardised feeding regimen used. The intake averaged $12.2 \mathrm{~g} / \mathrm{d}$ during the growth period and $13.0 \mathrm{~g} / \mathrm{d}$ during pregnancy. In the lactation period, three dams in each group did not completely consume the diet administered. These dams and their litters were excluded from the experiment. The average diet intake of the remaining fourteen dams during the lactation period was $24.7 \mathrm{~g} / \mathrm{d}$. The body-weight gain of the female rats did not differ between both groups during the whole period (Fig. 1).

\section{Numbers of pregnancies, numbers of pups born and weights of pups and litters at birth}

The number of pregnancies was ten in both groups, corresponding to $83 \%$ of the mated rats. The number of total pups born and pups born alive per dam were not different between dams fed oxidised oil and dams fed fresh oil (Table 3). Dams fed oxidised oil had 0.5 (SD 0.7) ( $n$ 10) stillborn pups; in the group of dams fed fresh oil there were no stillborn pups. Litters of dams fed oxidised oil were lighter at birth than those of dams fed fresh oil. Body weights of individual pups of dams fed oxidised oil were lower than those of pups of dams fed fresh oil (least square mean value $4.55(\mathrm{SD} \mathrm{0.12)}$ v. $5.28(\mathrm{SD} 0.12) \mathrm{g}, n 7 ; P<0.001)$.

\section{Development of litters during the suckling period}

At days 1, 14 and 19 of lactation, litters, standardised to seven pups each, of the dams fed the oxidised oil were

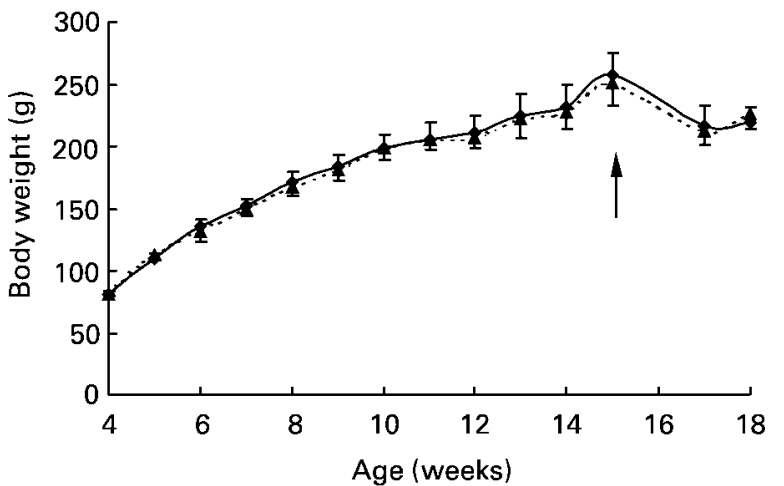

Fig. 1. Body weight of female rats fed diets containing fresh $(\bullet)$ or oxidised $(\boldsymbol{\Delta})$ oil. Arrow indicates time of parturition. For details of diet and procedures, see Tables 1 and 2 and pp. 268-269. Values are means for seven rats per group with standard deviations shown by vertical bars. The mean values were not significantly different between the two groups at any time point.

Table 3. Number of rats born and weights of individual pups and litters at birth of dams fed diets containing fresh oil or oxidised oil† (Mean values and standard deviations)

\begin{tabular}{|c|c|c|c|c|}
\hline & \multicolumn{2}{|c|}{$\begin{array}{l}\text { Fresh oil } \\
\quad(n 10)\end{array}$} & \multicolumn{2}{|c|}{$\begin{array}{l}\text { Oxidised oil } \\
\quad(n 10)\end{array}$} \\
\hline & Mean & SD & Mean & SD \\
\hline \multicolumn{5}{|l|}{ Rats born $(n)$} \\
\hline Total & $12 \cdot 7$ & 2.5 & $13 \cdot 5$ & $2 \cdot 1$ \\
\hline Alive & $12 \cdot 7$ & $2 \cdot 5$ & $13 \cdot 0$ & $2 \cdot 0$ \\
\hline Weights of litters at birth (g) & $67 \cdot 0$ & $7 \cdot 6$ & $58 \cdot 9^{\star}$ & $9 \cdot 4$ \\
\hline
\end{tabular}

Mean values were significantly different from those of the group fed fresh oil: ${ }^{*} P<0.05$.

†For details of diets and procedures see Tables 1 and 2 and pp. 268-269.

lighter than those of the dams fed the fresh oil (Table 4). Weight gains of litters from day 1 to day 19 were also lower in dams fed oxidised oil than in dams fed fresh oil. At day 19, suckling pups of rats fed oxidised oil had a higher concentration of fat, a lower concentration of

Table 4. Weight gain of litters and body composition of pups of dams fed diets containing fresh oil or oxidised oil during the suckling period $\dagger$

(Mean values and standard deviations)

\begin{tabular}{|c|c|c|c|c|}
\hline & \multicolumn{2}{|c|}{$\begin{array}{l}\text { Fresh oil } \\
\quad(n 7)\end{array}$} & \multicolumn{2}{|c|}{$\begin{array}{l}\text { Oxidised oil } \\
(n 7)\end{array}$} \\
\hline & Mean & SD & Mean & SD \\
\hline \multicolumn{5}{|l|}{ Weight of litters $(\mathrm{g})$} \\
\hline Day 1 & $37 \cdot 3$ & $3 \cdot 6$ & $32 \cdot 0^{\star}$ & $2 \cdot 1$ \\
\hline Day 7 & $74 \cdot 4$ & $3 \cdot 7$ & $72 \cdot 7$ & $7 \cdot 5$ \\
\hline Day 14 & 144 & 14 & $127^{*}$ & 9 \\
\hline Day 19 & 202 & 16 & $166^{\star}$ & 24 \\
\hline $\begin{array}{l}\text { Weight gain of litters from day } \\
1 \text { to day } 19\end{array}$ & 164 & 14 & $133^{*}$ & 23 \\
\hline \multicolumn{5}{|c|}{ Composition of carcasses of suckling pups at day 19} \\
\hline Protein (g/kg carcass) & 614 & 25 & $520^{\star}$ & 106 \\
\hline Fat (g/kg carcass) & 220 & 28 & $295^{\star}$ & 94 \\
\hline Protein/fat $(\mathrm{g} / \mathrm{g})$ & $2 \cdot 85$ & 0.54 & $2 \cdot 03^{\star}$ & 1.00 \\
\hline
\end{tabular}

Mean values were significantly different from those of the group fed fresh oil: ${ }^{\star} P<0.05$.

†For details of diets and procedures see Tables 1 and 2 and pp. 268-269. 
protein and a lower protein:fat ratio in their carcasses than suckling pups of rats fed fresh oil.

\section{Concentrations of nutrients and antioxidative status of the milk}

Milk of rats fed the oxidised oil had a lower concentration of triacylglycerols and a lower energy content than milk of rats fed the fresh oil (Table 5). The concentrations of protein and lactose were not different between milk of rats fed the fresh oil and those fed the oxidised oil. Concentrations of LHP and $\alpha$-tocopherol and the antioxidant capacity of the milk were also not different between both groups.

\section{Concentrations of lipid peroxidation products and} $\alpha$-tocopherol in livers of dams, newborn and suckling pups

In dams fed the oxidised oil, the concentrations of TBARS, LHP, 7 $\beta$-hydroxycholesterol and 7-ketocholesterol in the liver were 1.7-, 2.0-, 7.7- and 16.0-fold greater respectively, while the concentration of $\alpha$-tocopherol was $48 \%$ lower than in dams fed fresh oil (Fig. 2). In newborn pups, the concentration of TBARS in the liver was not different between the groups. The concentration of LHP in the liver was nearly 2-times greater in newborn pups of dams fed oxidised oil than in newborn pups of dams fed fresh oil; the concentration of $\alpha$-tocopherol in the liver of newborn pups of dams fed oxidised oil was only $44 \%$ of that of newborn pups of dams fed fresh oil. In suckling pups, concentrations of TBARS and $7 \beta$-hydroxycholesterol in the liver did not differ between both groups. The concentrations of LHP and 7-ketocholesterol in the livers of suckling pups of dams fed oxidised oil were more than double those of suckling pups of dams fed fresh oil. The concentration of $\alpha$-tocopherol in

Table 5. Energy content, concentrations of nutrients, lipid hydroperoxides and $\alpha$-tocopherol and antioxidative status of the milk of dams fed diets containing a fresh oil or an oxidised oil at day 14 of lactation†

(Mean values and standard deviations)

\begin{tabular}{|c|c|c|c|c|}
\hline & \multicolumn{2}{|c|}{$\begin{array}{l}\text { Fresh fat } \\
\qquad(n 7)\end{array}$} & \multicolumn{2}{|c|}{$\begin{array}{l}\text { Oxidised fat } \\
(n 7)\end{array}$} \\
\hline & Mean & SD & Mean & SD \\
\hline $\begin{array}{l}\text { Energy content } \\
(\mathrm{kJ} / \mathrm{kg})\end{array}$ & 7950 & 2390 & $5000^{*}$ & 1760 \\
\hline $\begin{array}{l}\text { Protein } \\
(\mathrm{g} / \mathrm{l})\end{array}$ & 81 & 9 & 73 & 7 \\
\hline $\begin{array}{l}\text { Triacylglycerols } \\
\text { (mmol/l/) }\end{array}$ & 204 & 86 & $97^{\star}$ & 50 \\
\hline $\begin{array}{l}\text { Lactose } \\
\quad(\mathrm{mmol} / \mathrm{l})\end{array}$ & 88 & 33 & 96 & 13 \\
\hline $\begin{array}{l}\text { Lipid hydroperoxides } \\
\qquad(\mu \mathrm{mol} / \mathrm{l})\end{array}$ & 28 & 15 & 28 & 10 \\
\hline $\begin{array}{l}\alpha \text {-Tocopherol } \\
(\mu \mathrm{mol} / \mathrm{l})\end{array}$ & 36 & 22 & 37 & 14 \\
\hline $\begin{array}{l}\text { Antioxidant capacity } \\
\qquad(\mathrm{mmol} / \mathrm{l})\end{array}$ & 1.09 & 0.04 & 1.06 & 0.03 \\
\hline
\end{tabular}

Mean values were significantly different from those of the group fed fresh oil: ${ }^{\star} P<0.05$.

†For details of diets and procedures see Tables 1 and 2 and pp. 268-269. the liver was higher in suckling pups of dams fed oxidised oil than in those fed the fresh oil.

Concentrations of triacylglycerols and cholesterol in livers of dams, and in newborn and suckling pups

Dams fed oxidised oil had lower concentrations of triacylglycerols and cholesterol in the liver than dams fed fresh oil (Fig. 3). Newborn pups of dams fed oxidised oil tended to have lower concentrations of triacylglycerols and had significant lower concentrations of cholesterol in the liver than those of dams fed the fresh oil; concentrations of triacylglycerols and cholesterol in the liver of 19-d-old suckling pups did not differ between the groups.

\section{Discussion}

When investigating the effects of lipid peroxidation products in thermoxidised oils, special consideration must be given to the fatty acid composition of the oil and the treatment conditions, because both affect formation and amount of lipid peroxidation products. The oil used in the present study had high amounts of PUFA and was heated at a relatively low temperature over a long time. This treatment caused a considerable loss of PUFA and an accumulation of high concentrations of both primary lipid peroxidation products, such as peroxides and hydroperoxides, and secondary lipid peroxidation products, such as carbonyls and total polar compounds. In contrast to most other studies dealing with the effects of thermoxidised fats, the fresh and the oxidised oils used in the present study were equalised for their fatty acid composition as well as their $\alpha$-tocopherol concentration. Therefore, the effects observed in animals fed oxidised oil can be attributed predominately to lipid peroxidation products present in the oxidised oil. Moreover, due to the controlled feeding system (i.e. identical feed intake of both groups) rats fed the oxidised oil did not differ in their growth from those fed the fresh oil. This fact is advantageous from the view of methodology, because the effects of oxidised oils were not confounded by secondary effects of reduced growth. Despite the restricted-feeding regimen used in our present study, the female rats received enough energy for adequate growth. The mean bodyweight gain during the growth period was $2.3 \mathrm{~g} / \mathrm{d}$, which is in accordance with normal growth rates of female Sprague-Dawley rats (National Research Council, 1995). Interfering effects of trans-fatty acids or conjugated linoleic acids can also be excluded, because both dietary oils had equal low amounts of these fatty acid isomers.

To study the effect of lipid peroxidation products in oxidised oils on the formation of lipid peroxidation in the rats, we performed the TBARS assay, the FOX method, and determined the concentrations of various oxysterols in the liver, a tissue that reacts sensitively to dietary oxidative stress. The TBARS assay is a widely used method for quantification of decomposition products of fatty acids. However, this method is rather unspecific and includes products that are generated during the assay. In contrast to the TBARS assay, the FOX method which is based on the formation of the $\mathrm{Fe}(\mathrm{III})-\mathrm{xylenol}$ orange complex, reflects a 

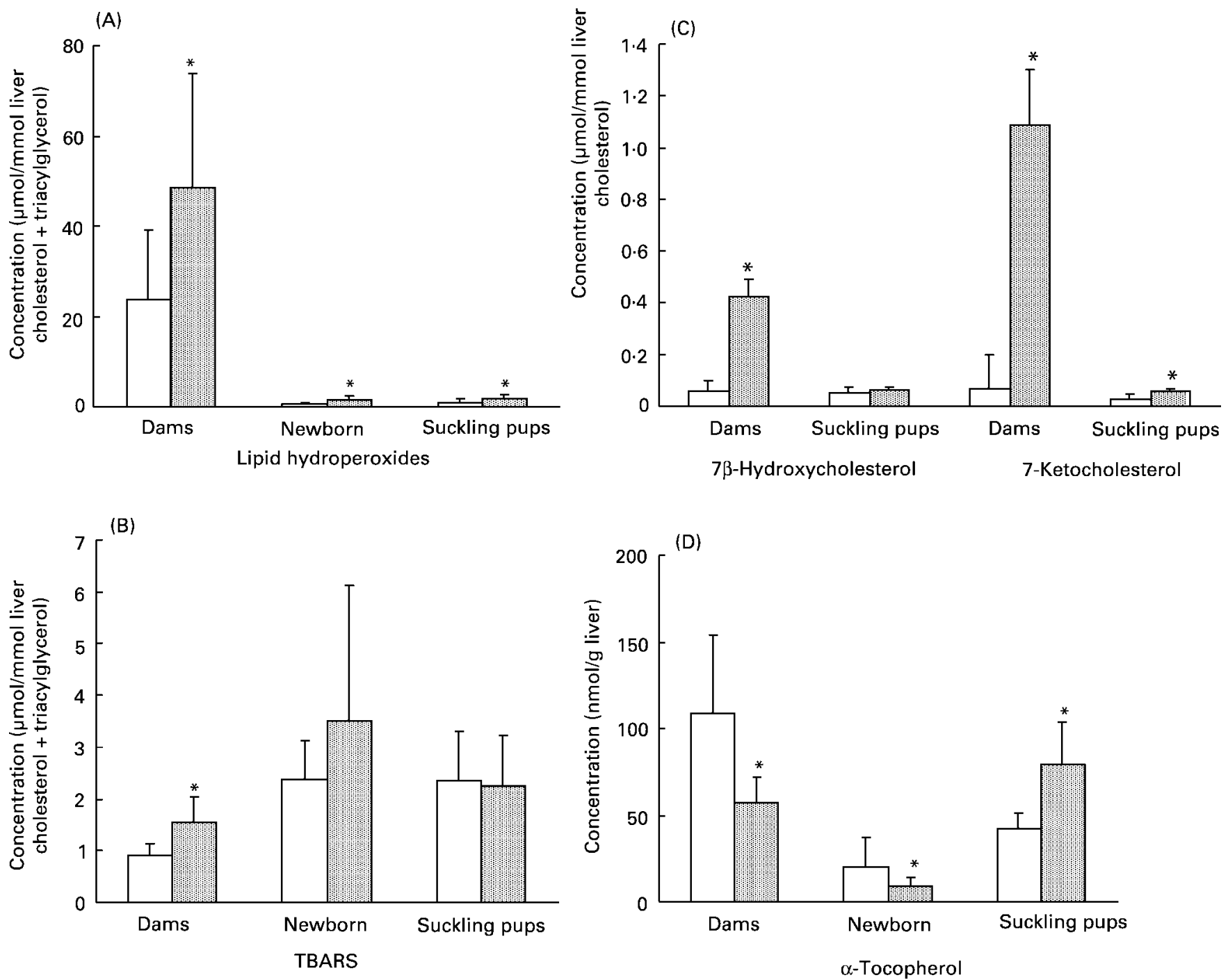

Fig. 2. Concentrations of lipid hydroperoxides (A), thiobarbituric acid reactive-substances (TBARS; (B)), 7 $\beta$-hydroxycholesterol and 7-ketocholesterol (C) and $\alpha$-tocopherol (D) in livers of dams fed diets containing fresh ( $\square$ ) or oxidised (回) oil, and in their newborn and 19-d-old suckling pups. For details of diet and procedures, see Tables 1 and 2 and pp. 268-269. Values are means for seven (dams and suckling pups) or ten (newborn) rats per group with standard deviations shown by vertical bars. Mean values were significantly different from those of the groups fed fresh oil: ${ }^{*} P<0.05$.

chemical amplification of the original level of LHP present in tissue extracts. Peroxidisable lipids do not influence the assay (Hermes-Lima et al. 1995). The concentrations of 7ß-hydroxycholesterol and 7-ketocholesterol are considered to be highly specific variables of lipid peroxidation (Adachi et al. 2001). They are formed from cholesterol by non-enzymic oxidation, predominately in the course of oxidation of PUFA (Björkhem, 2002). High concentrations of $7 \beta$-hydroxycholesterol are therefore an indicator of oxidative stress (Breuer \& Björkhem, 1995). The observation that female rats fed oxidised oil had markedly higher concentrations of those lipid peroxidation products and lower concentrations of $\alpha$-tocopherol in the liver than rats fed the fresh oil, confirms recent studies that showed that oxidised dietary lipids are a source of oxidative stress (Liu \& Huang, 1995). As in recent studies (Eder \& Kirchgessner, 1998; Chao et al. 2001; Eder et al. 2003), feeding a diet with an oxidised oil lowered the concentrations of triacylglycerols and cholesterol in the liver. This might be due to an inhibition of hepatic lipogenesis (Eder \& Kirchgessner, 1998; Eder et al. 2003) and a stimulation of the lipid catabolism in the liver by activation of the PPAR $\alpha$ (Martin et al. 2000; Chao et al. 2001).

The concentrations of TBARS and LHP in the liver of newborn rats suggests that feeding a diet with an oxidised oil to female rats during pregnancy also causes oxidative stress to their fetuses. This agrees with studies that demonstrated a close relationship between the antioxidant status of pregnant rats and their fetuses (Viana et al. 1999; Arikan et al. 2001). In particular, a close relationship between tocopherol concentrations in maternal and fetal tissues was found (Viana et al. 1999). Reduced tocopherol concentrations in the livers of fetuses of rats fed the oxidised oil might be due to the low tocopherol status of their mothers. Increased concentrations of lipid peroxidation products in the livers of fetuses of dams fed the 
(A)

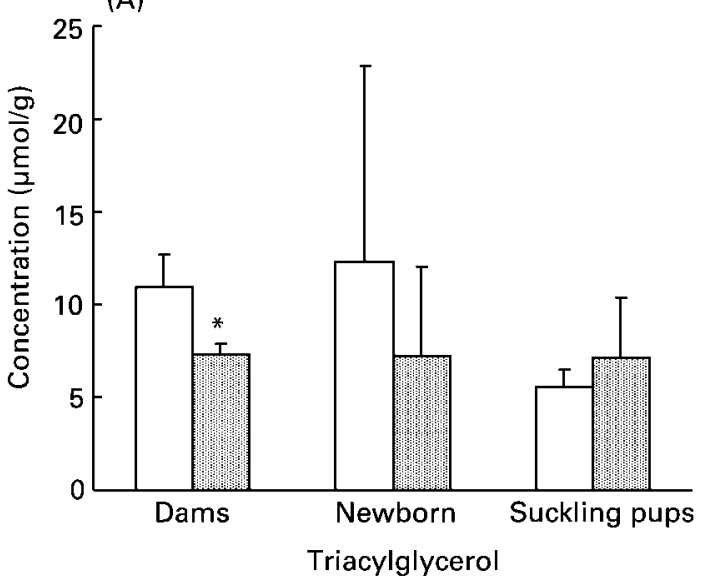

(B)

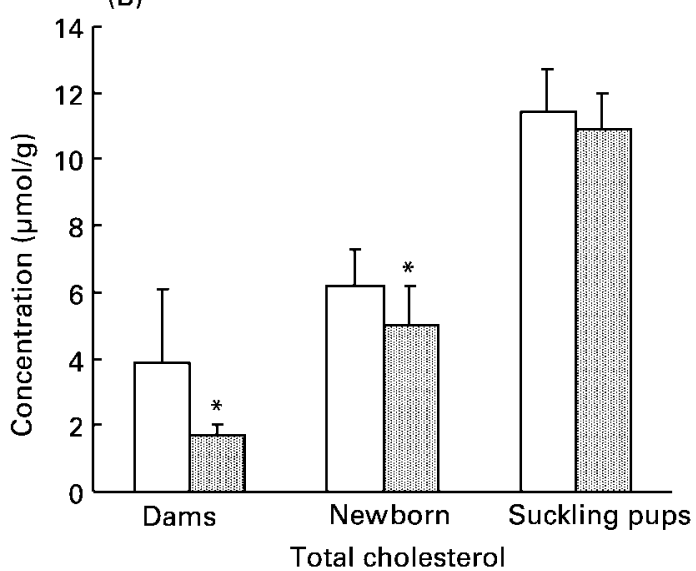

Fig. 3. Concentrations of triacylglycerols (A) and cholesterol (B) in livers of dams fed diets containing fresh $(\square)$ or oxidised (國) oil and their newborn or 19-d-old suckling pups. For details of diet and procedures, see Tables 1 and 2 and pp. 268-269. Values are means for seven (dams and suckling pups) or ten (newborn) rats per group with standard deviation represented by vertical bars. Mean values were significantly different from those of the groups fed fresh oil: ${ }^{*} P<0.05$.

oxidised oil could occur for different reasons. First, they could be due to the transfer of lipid peroxidation products from maternal blood through the placenta. A trans-placental transfer of various lipid peroxidation products such as ketones and malondialdehyde in rats has been reported (Rogers et al. 1999; Herrera, 2002). Second, increased concentrations of lipid peroxidation products in the liver could be due to lower concentrations of $\alpha$-tocopherol in the liver. It is well known that a reduced tocopherol status in the liver leads to increased concentrations of lipid peroxidation products (Ringseis \& Eder, 2002). Oxidative stress during the fetal phase could be the reason for the increased rate of mortality and the reduced body weights at birth observed in newborn rats of dams fed the oxidised oil. Several studies have shown that oxidative stress in fetuses, such as that induced by ethanol intake or diabetes of their mothers, causes deformation and reduces their body weight (Henderson et al. 1999; Viana et al. 2000). By supplementation of mothers with dietary antioxidants, the effects of oxidative stress on body weights and deformations of fetuses could be reduced (Cederberg et al. 2001).

Newborn rats of dams fed the oxidised oil had reduced concentrations of triacylglycerols and cholesterol in the liver, similar to their mothers. We assume that lipid peroxidation products in the liver caused similar effects on the lipid metabolism in newborn rats as in their mothers. The finding that the concentrations of triacylglycerols and cholesterol in the liver of suckling pups were not different between both groups suggests that the lipid metabolism in pups of dams fed the oxidised oil was normalised during the suckling period.

The observation that the concentrations of lipid peroxidation products and $\alpha$-tocopherols in the milk and its antioxidative status were not influenced by feeding the oxidised oil was surprising. In dairy cows, sows and human subjects, a correlation between the $\alpha$-tocopherol concentration of plasma and that of milk was reported (Focant et al. 1998; Baldi et al. 2000; Mahan et al. 2000). Because of their lower vitamin E status, we expected lower $\alpha$-tocopherol concentrations in the milk of rats fed the oxidised oil. Lipid peroxidation products in the milk derive mainly from the liver; the liver secretes lipid peroxidation products via lipoproteins, which are taken up by peripheral tissues (Vine et al. 1998). Since the concentrations of lipid peroxidation products in the liver were increased in rats fed the oxidised oil we also expected increased concentrations of lipid peroxidation products in their milk. Based on the results of the present study, the effects of a dietary oxidised oil on the antioxidant status and the concentrations of lipid peroxidation products and $\alpha$-tocopherol cannot be explained. Increased concentration of $\alpha$-tocopherol in the liver of suckling pups of dams fed the oxidised oil is another finding that cannot be explained at present. In a study of Lauridsen et al. (2002), the concentration of $\alpha$-tocopherol in the liver of piglets markedly increased during the suckling period. However, it is not clear why in our present study the $\alpha$-tocopherol concentration in the livers of suckling pups of dams fed the oxidised oil rose more during the suckling period than that of suckling pups of dams fed the fresh oil.

The finding that the concentrations of lipid peroxidation products in the milk were not different between dams fed the fresh oil and those fed the oxidised oil suggests that suckling pups of dams fed the oxidised oil were not subjected to dietary oxidative stress during the suckling period. Therefore, increased hepatic concentrations of 7-ketocholesterol and LHP in suckling pups of dams fed the oxidised oil may be derived from the prenatal phase.

Another interesting finding of the present study is that during the suckling period pups of dams fed an oxidised oil grew more slowly than pups of dams fed a fresh oil. This could be due to the reduced fat and energy content in the milk of dams fed the oxidised oil. It is difficult to explain, however, why pups of dams fed the oxidised oil and pups of dams fed the fresh oil differed in their body composition. Because the protein concentration of the milk was not different between dams of both groups, we believe that a reduced protein accretion in pups of dams fed the oxidised oil was not due to a lower supply with 
protein. It is possible that the growth and body composition of pups after suckling were already determined by intrauterine nutrition of the fetuses.

In conclusion, the present study shows that feeding of oxidised oils containing high concentrations of lipid peroxidation products to female rats during rearing, pregnancy and lactation influences development of fetuses and suckling pups as well as their antioxidant status and lipid metabolism. At present, many of the effects observed in the present study cannot be explained and should be subject to further investigation.

\section{Acknowledgements}

The skilful technical assistance of Mrs I. Kaiser and $\mathrm{Mr} \mathrm{W}$. Böttcher is gratefully acknowledged.

\section{References}

Adachi J, Kudo R, Ueno Y, Hunter R, Rajendram R, Want E \& Preedy VR (2001) Heart 7-hydroperoxycholesterol and oxysterols are elevated in chronically ethanol-fed rats. J Nutr 131, 2916-2920.

AOAC International (2001) Basic Calculations for Chemical and Biological Analysis, 2nd ed. [BJS Efiok and EE Eduok, editors]. Gaithersberg, MD: AOAC International.

Arikan S, Konukoglu D, Arikan C, Akcay T \& Davas I (2001) Lipid peroxidation and antioxidant status in maternal and cord blood. Gynecol Obstet Invest 51, 145-149.

Atwater WO \& Bryant AP (1900) The availability and food values of food materials. In 12th Annual Report of the Storrs, CT, Agricultural Experimental Station, pp. 73-110. Storrs, CT: University of Connecticut.

Baldi A, Savioni G, Pinotti L, Monfardini E, Cheli F \& Dell'Orto $\mathrm{V}$ (2000) Effects of vitamin $\mathrm{E}$ and different energy sources on vitamin $\mathrm{E}$ status, milk quality and reproduction in transition cows. J Vet Med A Physiol Pathol Clin Med 47, 599-608.

Balz M, Schulte E \& Thier H-P (1993) Simultaneous determination of $\alpha$-tocopherol acetate, tocopherols and tocotrienols by HPLC with fluorescence detection in foods. Fat Sci Technol 95, 215-220.

Björkhem I (2002) Do oxysterols control cholesterol homeostasis? J Clin Invest 110, 725-730.

Blanc P, Revol A \& Pacheco H (1992) Chronical ingestion of oxidized oil in the rat: effect on lipid composition and on cytidylyl transferase activity in various tissues. Nutr Res 12, 833-844.

Borsting CF, Engberg RM, Jakobsen K, Jensen SK \& Andersen JO (1994) Inclusion of oxidized fish oil in mink diets. 1. The influence on nutrient digestibility and fatty acid accumulation in tissues. J Anim Physiol Anim Nutr 72, 132-145.

Bradford MM (1976) A rapid and sensitive method for the quantitation of microgram quantities of protein utilizing the principle of protein-dye binding. Anal Biochem 72, 248-254.

Brandsch C, Ringseis R \& Eder K (2002) High dietary iron concentrations enhance the formation of cholesterol oxidation products in the liver of adult rats fed salmon oil with minimal effects on antioxidant status. $J$ Nutr 132, 2263-2269.

Breuer O \& Björkhem I (1995) Use of an ${ }^{18} \mathrm{O}_{2}$ inhalation technique and mass isotopomer distribution analysis to study oxygenation of cholesterol in rat. Evidence for in vivo formation of 7-oxo-, 7 beta-hydroxy-, 24-hydroxy-, and 25-hydroxycholesterol. J Biol Chem 270, 20278-20284.
Cederberg J, Siman CM \& Eriksson UJ (2001) Combined treatment with vitamin $\mathrm{E}$ and vitamin $\mathrm{C}$ decreases oxidative stress and improves fetal outcome in experimental diabetic pregnancy. Pediatr Res 49, 755-762.

Chao PM, Chao CY, Lin FJ \& Huang C (2001) Oxidized frying oil up-regulates hepatic acyl-CoA oxidase and cytochrome $\mathrm{P} 4504 \mathrm{~A} 1$ genes in rats and activates PPARalpha. J Nutr 131, 3166-3174.

Cho SH \& Choi YS (1994) Lipid peroxidation and antioxidant status is affected by different vitamin E levels when feeding fish oil. Lipids 29, 47-52.

De Hoff JL, Davidson JH \& Kritchevsky V (1978) An enzymatic assay for determining free and total cholesterol in tissues. Clin Chem 24, 433-435.

Deutsche Gesellschaft für Fettwissenschaft (1994) Einheitsmethoden zur Untersuchung von Fetten, Fettprodukten, Tensiden und verwandten Stoffen. (Standard Methods for Analysis of Fats, Fat Products, Tensides and Related Substances). Stuttgart: Wissenschaftliche Verlagsgesellschaft.

Eder K \& Kirchgessner M (1998) The effect of dietary vitamin E supply and a moderately oxidized oil on activities of hepatic lipogenic enzymes in rats. Lipids 33, 277-283.

Eder K, Suelzle A, Skufca P, Brandsch C \& Hirche F (2003) Effects of dietary thermoxidized fats on expression and activities of lipogenic enzymes in rats. Lipids 38, 31-38.

Endo Y, Li CM, Tagiri-Endo M \& Fujimoto K (2001) A modified method for the estimation of total carbonyl compounds in heated and frying oils using 2-propanol as a solvent. $\mathrm{J} \mathrm{Am}$ Oil Chem Soc 78, 1021-1024.

Engberg RM, Lauridsen C, Jensen SK \& Jakobsen K (1996) Inclusion of oxidized vegetable oil in broiler diets. Its influence on nutrient balance and on the antioxidative status of broilers. Poult Sci 75, 1003-1011.

Focant M, Mignolet E, Marique M, Clabots F, Breyne T, Dalemans D \& Larondelle Y (1998) The effect of vitamin E supplementation of cow diets containing rapeseed and linseed on the prevention of milk fat oxidation. J Dairy Sci 81, 1095-1101.

Halliwell B \& Gutteridge JM (1989) Free Radicals in Biology and Medicine. Oxford: Clarendon Press.

Hara A \& Radin SN (1978) Lipid extraction of tissues with a lowtoxicity solvent. Anal Biochem 90, 420-426.

Henderson GI, Chen JJ \& Schenker S (1999) Ethanol, oxidative stress, reactive aldehydes, and the fetus. Front Biosci 15, $541-550$.

Hermes-Lima M, Willmore WG \& Storey KB (1995) Quantification of lipid peroxidation in tissue extracts based on Fe(III)xylenol orange complex formation. Free Radic Biol Med 19, 271-280.

Herrera E (2002) Lipid metabolism in pregnancy and its consequences in the fetus and newborn. Endocrine 19, 43-55.

International Union of Pure and Applied Chemistry (2000) Determination of polar compounds, polymerized and oxidized triacylglycerols, and diacylglycerols in oils and fats. Pure Appl Chem 72, 1563-1575.

Lauridsen C, Engel H, Jensen SK, Craig AM \& Traber MG (2002) Lactating sows and suckling piglets preferentially incorporate RRR- over all-rac-alpha-tocopherol into milk, plasma and tissues. J Nutr 132, 1258-1264.

Liu JF \& Huang CJ (1995) Tissue $\alpha$-tocopherol retention in male rats is compromised by feeding diets containing oxidized frying oil. J Nutr 125, 3071-3080.

Mahan DC, Kim YY \& Stuart RL (2000) Effect of vitamin E sources (RRR- or all-rac-alpha-tocopheryl acetate) and levels on sow reproductive performance, serum, tissue, and milk alpha-tocopherol contents over a five-parity period, and the effects on the progeny. J Anim Sci 78, 110-119. 
Martin JC, Joffre F, Siess MH, Vernevaut MF, Collenot P, Genty M \& Sebedio JL (2000) Cyclic fatty acid monomers from heated oil modify the activities of lipid synthesizing and oxidizing enzymes in rat liver. $J$ Nutr 130, 1524-1530.

Mori TA, Croft KD, Puddey IB \& Beilin LJ (1996) Analysis of native and oxidized low-density lipoprotein oxysterols using gas chromatography-mass spectrometry with selective ion monitoring. Redox Rep 2, 25-34.

National Research Council (1995) Nutrient Requirements of Laboratory Animals. Washington, DC: National Academy Press.

Recknagel RO \& Glende EA Jr (1984) Spectrophotometric detection of lipid conjugated dienes. Methods Enzymol 105, $331-337$.

Ringseis R \& Eder K (2002) Insufficient dietary vitamin E increases the concentration of 7beta-hydroxycholesterol in tissues of rats fed salmon oil. J Nutr 132, 3732-3735.

Rogers MS, Mongelli M, Tsang KH \& Wang CC (1999) Fetal and maternal levels of lipid peroxides in term pregnancies. Acta Obstet Gynecol Scand 78, 120-124.

Sidwell CG, Salwin H, Benca M \& Mitchell JH Jr (1954) The use of thiobarbituric acid as a measure of fat oxidation. $\mathrm{J} \mathrm{Am} \mathrm{Oil}$ Chem Soc 31, 603-606.

Viana M, Aruoma OI, Herrera E \& Bonet B (2000) Oxidative damage in pregnant diabetic rats and their embryos. Free Radic Biol Med 29, 1115-1121.

Viana M, Barbas C, Castro M, Herrera E \& Bonet B (1999) Alpha-tocopherol concentration in fetal and maternal tissues of pregnant rats supplemented with alpha-tocopherol. Ann Nutr Metab 43, 107-112.

Vine DF, Mamo CL, Beilin LJ, Mori TA \& Croft KD (1998) Dietary oxysterols are incorporated in plasma triglyceriderich lipoproteins, increase their susceptibility to oxidation and increase aortic cholesterol concentration of rabbits. J Lipid Res 39, 1995-2004. 